be entirely altered. Strychnia is said by some of our leading neurologists to be decomposed in the stomach. No doubt this is the case, but yet it is not rendered quite an inert substance even when taken by the mouth.

I have injected the nitrate of strychnia subcutaneously in doses of $I_{1}^{1} \frac{1}{0}$ th grain and I can testify that its bitter taste can be distinctly recognised in the mouth and the appetite is notably increased. It is this bitter and tonic effect that is probably one of its most valuable qualities. One grain of strychnia dissolved in 70,000 grains of water, equal to one gallon, is said to be distinctly tasted by its bitterness. In these degenerate days, when drugs are said to be entirely useless by some, I for one should be sorry to see strychnia classed as one of the effete substances. have seen poisoning by strychnia in piegnancy with violent convulsions, but without any evidence of uterine contraction. The late Dr. Ramskill used to say that he always gave very large doses of strychnia, but what this quantity was, I have never heard him say. The dose of strychnia in some of the books is from $\frac{1}{60}$ th to $1 \frac{1}{5}$ th grain, Martindale and Westcott, ninth edition, 1898 ; from 30 th grain to 1 grain, Squire's "Companion to the British Pharmacopoeia," 1874; $\frac{1}{2} 6$ th grain has poisoned a child, Taylor's "Medical Jurisprudence," 1874 ; $\frac{1}{2}$ grain has poisoned an adult, ibid. I am, Sirs, yours faithfully,

Albert S. Morton, M.D. Durh.

Putney, S.W., Feb. 6th, 1907.

\section{A CASE OF DORSAL DISPLACEMENT OF THE ARM IN VERTEX PRESENTATION.}

\section{To the Editors of THE LANCFT.}

SiRs, -In THE LANCET of Jan. 19th, p. 165, an interesting case is reported by Dr. Arthur G. Wells under this heading. We are told that from the abdominal examination the case was diagnosed as one of second position of the child, but we are not told if the internal examination confirmed this. I venture to suggest that the case might have been one of third position of the child and then the displacement of the arm is easily explained. With the sudden rupture of membranes the left hand and arm came down over the face as is not an uncommon occurrence in vertex presentation, especially with escape of excess of liquor amnii. When the head was well in the pelvis the final long rotation occurred, but the arm did not rotate with the head. The face, the side of the head, and the occiput rotated in turn under the arm, and finally the left hand and arm were to the back of the occiput and to the left side of the child's neck, distending the right side of the perineum of the mother, as was seen in the case reported.

I should be interested to hear if the vaginal examination confirmed the abdominal, or if the vertex were too high up for a definite diagnosis. Also, if it were the left arm that was displaced. Much the same difficulty might occur with extracting a head with arms extended if the body were rotated in the wrong direction. In this case the backward displaced arm could not be liberated until the head had been rotated back again.-I am, Sirs, yours faithfully,

F. E. TuRLE EVANS, L.R.C.P., L.R.C.S. Edin.

Willesden Junction, N.W., Feb. 6th, 1907.

\section{THE CURRANT AS A FOOD.}

\section{To the Editors of THE LANCET.}

SrRs, - It seems inexplainable that the medical profession generally has expressed no opinion upon the present craze for the use of currants in bread and other forms of food. At some of our principal stores currant Joaves and other forms of eatables with currants as ingredients are exposed for sale and labelled "as recommended by (bere follows the name of a well-known practitioner)." The ethics of this legend I do not now question, but $I$ think that the wholesomeness of currants as they exist in currant loaves, \&c., is a matter of opinion and calls for discussion. If the admixture of currants with bread is really a useful and nourishing form of food, good and well, let it continue; but $I$ have no hesitation in stating that currants are neither a useful nor a wholesome addition to our bread and therefore to be condemned. Anyone having experience of children and their dietetic ailments must be aware of the effect of currants upon children. The currant is not digested by children; it is usually passed whole and is the commonest cause of stomach-ache and diarrhoea after " children's parties."

How, then, has the currant attained so high hygienic fame recently? The experience of every household where there are children is against it. It is, in my opinion, wholly unworthy of such recognition as a food and is franght with danger to the gastro-intestinal tract of children especially. With adults it may be different; the very indigestibility of the currant may serve as an exciting factor to the intestine, especially the large bowel, and promote, it may be, much-needed peristalsis and laxity thereby. This seems its only virtue and if this is its chief or only function within the human economy it is well the fact should be stated. There is possibly a difference in the digestibility of currants according as they are used in bread or in a form such as obtains in, say, dumplings. In bread, by baking, the skin of the currant is dried to an extent that renders it wholly impervious to any digestive fluid ; it is possible, however, that in currant dumplings, Shelford puddings, \&c., the long boiling to which these are submitted may serve to soften the skin or by cracking it allow the contents to be extruded. By boiling currants may be rendered less indigestible but any article of diet with currants prepared by baking, as in bread and buns, or by frying, as in countess pudding, tartlets, cakes, and fritters, the currant becomes indigestible and serves not as a food but as a gastro-intestinal irritant. I write these notes in the hope that the opinions and experiences of others may be elicited.

I am. Sirs, yours faithfully,

James Cantlie, M.B. Aberd., F.R.C.S. Eng.

Harley-street, W., Feb."12th, 1907.

\section{AN IMPORTANT CORRECTION, \\ To the Editors of THE LANCEN.}

SIRS, - The Students' Union of St. Bartholomew's Hospital regrets very much that the name and address of $E$. D. Fitzgerald, M.R.C.S., of Castle Hill-avenue, Folkestone, was included in the "Obituary List of Bartholomew's Men" and published in the Students' Union Year-Book for 1906. The Students' Union wishes through your columns to inform Mr. Fitzgerald's friends and your readers generally that $\mathrm{Mr}$. Fitzgerald is alive and well and the Union hopes to be excused for any pain which has been caused by the mistake made. I am, Sirs, yours faithfully,

Feb. 7 th, 1907. S. TREVOR Davies,

\section{A CASE OF INOPERABLE CANCER TREATED WITH TRYPSIN.}

\section{To the Editors of THE LANCET.}

SIRs,-As bearing upon the case recorded by Dr. Bertram Abrahams under the above heading in THE LANCET of Feb. 9th I should be glad to be allowed to refer your readers to the notes of the following case.

On May 19th, 1906, Messrs. - agents in this country wrote to me for advice and particulars of trypsin treatment on behalf of the wife of a constituent of theirs in South America. Briefly, from the notes of the case inclosed to me it appeared that in May-September, 1904, the patient, aged 30 years, suffered from severe pain in the right breast, stomach indisposition, ill-healtb, and "neurasthenia," for which she was treated. In the latter month a small tumour of the size of a small nut was for the first time detected in the right breast which, in spite of daily injections of cacodylate of soda for some weeks, continued to grow. In December the breast and axillary glands were removed, with apparent recovery of health. In March-April, 1905, there was a return of pain and in July obvious recurrence of growth. At this time the patient placed herself under the care of a Chinese "herb doctor." The pains and swelling disappeared and she gained is pounds in weight. In October the patient had the misfortune to lose her father and to have a daughter ill with typhoid fever. The consequent anxiety, bad nights, and constant attendance on her daughter prevented her taking care of herself and resulted in relapse. In February, 1906, the pain increased in severity and sleep was impossible; small sores and excrescences appeared at the site of the operation, accompanied by great fotor. In April the sores had increased and pleuritic effusion was present. Morphia was re. sorted to in order to mitigate the pain, which otherwise was 
unbearable, but no sleep was secured and her weakness was becoming every day greater.

On May 21st I replied that it was "impossible for me to be of any use," and noting the date of the reportApril 16th-"I much fear the patient is beyond relief, as pleurisy is a most unfavourable sign." Two days after this opinion a cable message was received, advising the death of the patient.

I am, Sirs, yours faithfully,

London, Feb. 11th, 1907. JoHN A. SHAW-MACKENZIE, M.D. Lond.

\section{INTRAMEATAL OPERATIONS. To the Editors of THE LANCET.}

SIRs,-In answer to Mr. Macleod Yearsley's letter, which I overlooked till to-day, may I say that he does not point out what are the inaccuracies in my letter. But he makes certain statements which I take objection to. I have never used the word "wickedness" in connexion with any operation and certainly not concerning one that I have had occasionally to perform. Nor have I ever preached " universal otectomy." In my recent letter to THE LANCET I said : "Many cases do not require operation at all." Mr. Yearsley's reference to "universal irrigation," though the term is his own, is not so objectionable, as I still think that irrigation is the essential treatment in all cases of infected ears. Again, otectomy, to Greek scholars, would hardly signify "removal of the ear." My dictionary gives $\epsilon \kappa \tau o \mu \eta^{\prime}$ from $\dot{\epsilon} \kappa \tau \epsilon \mu \nu \omega=$ to cut out from. A cutting out of diseased tissues from the middle ear is an excellent definition of the operation I perform, and that, with provision of a free way for irrigation, is all that is generally required. I have seldom found it necessary to remove the outer attic wall. The removal of an ossicle is also often unnecessary, and why I should be forced to accept a term (ossiculectomy) which is actually misleading $I$ fail to understand. The term itself is hardly applicable to the removal of an ossicle. It is almost amusing to hear that several otologists have been in favour of intrameatal operations all along. I have been told that I was considered a crank for advocating such methods. I have read a great deal that has been written against intrameatal interference, but until I saw Mr. Yearsley's letter I had seen nothing of recent years that supported my views. Several of my patients have been advised against otectomy and are in consequence still suffering. Though $I$ cannot agree with all Mr. C. J. Heath says, he will perhaps permit me to quote from his paper published in THE LANCET of August 11th, 1906: "The paramount position which the radical operations hold in the estimation of otologists is a tacit acquiescence in the opinion that chronic suppuration of the midale ear is generally considered to be incurable by any other means."

You, Sirs, can bear witness that $I$ have not acquiesced in any such opinion, but I am afraid, in spite of $\mathrm{Mr}$. Yearsley, that there $\mathrm{I}$ as been much tacit acquiescence. I have not received any support at all from otologists, but if these cases can generally be cured without resort to a radical operation, which Mr. Yearsley is evidently beginning to believe, and which I can assure him is the fact, he should surely appear as a friend and not as a rather discourteous opponent. I am, Sirs, yours faithfully,

Coventry, Feb. 9th, 1907. F. FAULDER WHITE.

\section{BURIAL BY THE STATE.}

\section{To the Editors of THE LANOET.}

SIRs, - With all the talk about funeral reform and earthto-earth burial, it is a wonder that the matter of burial by the State has not been made a subject of practical legislation. It is a matter of growing and urgent importance when we come to consider the increase in population and the constquent increase in death, as well as the useless and unnecessary expense attendant on what nust naturally come to all of us

It is clearly evident that burial is compulsory, and starting with the modern Parliamentary and logical conclusion that what is compulsory should be free, or managed by the State, there should be no difficulty in arriving at the idea of civil or Government burial. We are bound by law to be registered at birth, educated, married legally, be it State, Church, or Registrar, free or at a fixed nominal cost; why, then, should there not be a similar enactment in case of death? she State undertaking to see what is necessarily compulsory is carried out in the best and most sanitary manner.
Government at present appoints medical officers of health to be of use whilst we are living, and coroners to inquire into the matter of sudden deaths, when at the most important time it leaves the relatives to carry out the burial in their own devious and insanitary manner. It would be most helpful and expedient for the State to appoint in every town a local burial official, who could on the death of anyone be duly notified by the doctor or relatives, and who would then proceed at once to take the matter of burial in hand by sending attendants to remove the body in an ambulance to a civic mortuary in or near the precincts of a cemetery, where it could lie until there were signs of dissolution and so prevent the horrors of what has occurred in many instances (many of which have been proved), viz., premature burial. On it becoming certain that death had taken place, the proper authorities would then proceed to the interment of the body in a wrapper or light covering, and so get a healthier and completely earth-to-earth burial. This would do away with the expense and present gruesomeness of encasing the body in a more or less ornamental coffin, which at present takes place in houses, many of which are far too small for the living, let alone the dead and in many cases infectiously deceased body (vide medica. reports). Total dissolution would thus take place in a more natural and less dangerous manner than by the present system and the gases generated would be not only not dangerous to the inhabitants of the vicinity, but, as scientists prove, would resolve themselves into the air and form component parts of pure atmosphere.

This system would certainly be preferable to the horrors of cremation, which cannot be viewed with calmness by the spectator, to say nothing of the expense and the prevention of any subsequent examination that might be required in cases of poisoning, and it can only be small satisfaction to have the ashes of the family in different urns about the house. Abraham of old was right when he said: "Let me bury my dead out of my sight," and if death is, as we are told, only a passing to a better life an example should be shown by the better educated not to make what must be, and is, a sad and solemn event into an unnecessary display of grief and show in dress and ancient mummery that can do no good to the departed and is often harmful and irksome to the spectators. The officer thus appointed would then be responsible for a proper register and relatives would be at far less trouble in getting records of death in case of wills, \&c., instead of having to search old and various registers, as is the case at present.

It only needs the statesman to come forward and formulate such a measure and lay the case before the public, so as to free them from false sentiment and prejudice, to achieve one of the greatest needed social and sanitary reforms of the twentieth century.

$$
\text { I am, Sirs, yours faithfully, }
$$

Langland Bay, near Swansea, Jan. 26th, 1907.

$$
\text { STEPBEN P. WILLS. }
$$

\section{MILK IN SMALL GENERAL SHOPS.}

\section{To the Editors of THE LANCET.}

SiRs,-In The LanceT of Jan. 26th Dr. G. Sowden, medical officer oi health of the borough of East Ham, calls attention to a statement made in an article by me on Milk in Small Genera: Shops, which appeared in THE LANCET of Jan. 19th, p. 193. The statement in question was to the effect that it had been asserted on excellent authority that about 70 per cent. of the total milk-supply of London is to be found in the small shops. I made a mistake. What I sbould have said was that more than 70 per cent. of the milk-selling premises of London are, according to excellent authority, situated in general shops. This means that the poorer classes obtain a very large proportion of their milk-supply from general provision shops.

From statistics given by Dr. Sowden it would seem that the proportion of dairies to provision shops which sell milk in East Ham is higher than in many parts of London, but Dr. Sowden speaks whereof he well knows and $I$ am in no way seekir $g$ to controvert his interesting information. There are too many insanitary provision shops which sell milk, though I bave unwittingly exaggerated the amount of milk sold in them. There is universal agreement among medical men that the insanitary conditions prevailing in provision shops are a distinct menace to the bealth of the consumersof young chi dren and infants in particular.

May $I$ add a few words to a letter already full long? 